\title{
Site control procedures for applicability and quality of Rapid Impulse Compaction
}

\author{
Przemysław Dobrzycki ${ }^{1}$ and Piotr Rychlewski ${ }^{2, *}$ \\ ${ }^{1}$ DABI SM BUDNY Sp. z o.o. Sp. k., Włościańska Str. 32, 43-518 Ligota, Poland \\ www.dabi.com.pl \\ ${ }^{2}$ Road and Bridge Research Institute, Instytutowa Str. 1, 03-302 Warsaw, Poland \\ www.ibdim.edu.pl
}

\begin{abstract}
Rapid development of foundation engineering and substrate improvement technologies and also availability of various enforcement techniques make that dynamic or vibration-related technologies are used in such accomplishments. They are distinguished with numerous advantages like fast execution and large bearing capacities resulting from good compaction or additional compaction of natural soils during executing the work. Among such technologies most often used are, inter alia, stone columns, impulse compaction, dynamic replacement and, finally, microexplosions. These technologies feature however some drawbacks like noise and vibrations. Noise is definitely more arduous for people. Although it is not more intense than that of standard work on construction site, but periodicity of noise source (e.g. vibrator, pile-driver) is oppressive for outsiders. Vibrations are generally better tolerated than noise. However, the influence of work exerted on neighbouring facilities should be under control. Accelerometers, which measure acceleration of structure elements caused by dynamic influences from working machinery, are used for this purpose. Another problem is the quality control of the work progressed. The paper provides both exemplary measurement equipment for vibration control and control procedures assessing efficiency of substrate improvement process.
\end{abstract}

\section{Introduction- Principles of Rapid Impulse Compaction}

As less and less areas are available for construction activity, the work must be run close to existing structures or residential buildings. While planning to use such methods on site, their influences on surroundings need to be considered and the unwanted effects need to be monitored continuously [1], [2], [3]. Dynamic economic development, consequently the urbanization and extension of road and railway infrastructure forces development of areas which not so long ago were considered as totally useless for construction purposes. However, due to new technologies, new perspectives are now opened for application of low-bearing soils and resources for building sector needs.

* Corresponding authors: przemyslaw.dobrzycki@dabi.com.pl, prychlewski@ibdim.edu.pl 
Not very long ago the low-bearing soils were recognized as totally worthless and almost always they were replaced. This causes large financial expenditure and extended work time, not to mention adverse effects for inhabitants and environment, such as increased traffic of heavy equipment and mandatory recycling of excavated spoil. Now, a sustainable and ecological building is promoted where emphasis is laid on limited use of natural resources and reduction of wastes and pollution resulting from building material transportation.

Concrete rubble gained, for instance, from demolition of old buildings, constructions or road pavement, can be an excellent building material used as fine fraction in concrete technology [4], [5] and in strengthening low-bearing soils as an alternative to their replacement, providing proper compacting, most often using impulse compaction method [6].
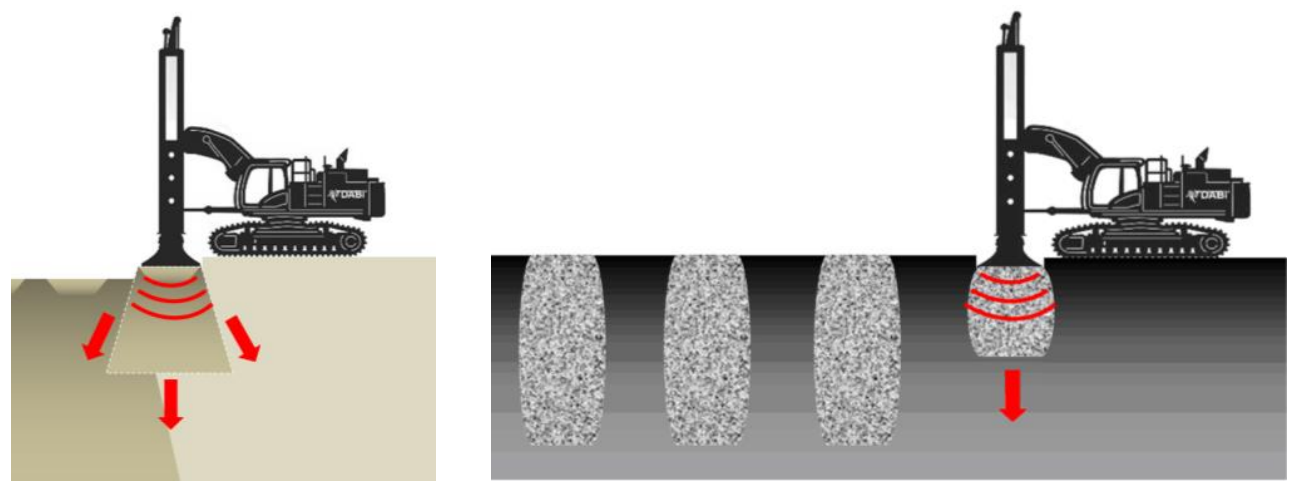

Fig. 1 Principle of Rapid Impulse Compaction (compaction, formation of stone columns).

Impulse Compaction / Rapid Impact Compaction is the effective and very efficient method of strengthening weak and non-consolidated soils down to medium depths. Impulse compaction process allows getting a distinct improvement of density index and mechanical properties of the soil processed. Impulse compaction technology can be applied wherever it is necessary to get better compaction of existing soil, to improve its strength and to reduce its settlement.

Impulse compacting is carried out with specialist machine on tracked excavator undercarriage with weight of about 60 tons, equipped with hydraulic hammer 5-12 tons, which is dropped at high frequency to a specially constructed steel foot of $1.5 \mathrm{~m}$ diameter, which - with each impact - submerges itself in soil and transmits energy to subsequent layers of soil substrate causing its compaction. The machine operates at the level of working platform at determined grid of points to get envisaged parameters. Impulse compactor is generally equipped with GPS guidance system which ensures that each point will be made at precise location on a plot, and with electronic control module, which monitors and records most important data of compacting process.

\subsection{Application of impulse compaction to non-cohesive soils}

Impulse compaction is most often used for sandy soils - sands, sandy gravels and gravels. Final effect of impulse compaction, independently of original condition, is a homogenous soil substrate of standardized properties [7, 8]. It is of special importance for soils of nonuniform degree of compaction or for areas with numerous voids or caverns. A real effect of compaction, depending on the type of soil, reaches down to 4-6 m. Re-aggregation of natural soil grains requires a considerable amount of energy which fans out and affects neighbouring structures. Numerous references provide methods used to measure these effects with respect to normative requirements [9-13]. 


\subsection{Application of impulse compaction for cohesive and organic soils - formation of stone columns}

Experience has taught us that impulse compaction method may be also used to improve cohesive soils, organic soils and man-made fills, and to treat industrial waste lagoons, municipal and mine waste dumps. In such soils, the impulse compaction method is most often used to form stone columns filled mainly with concrete rubble coming, inter alia, from recycling. Impulse technology allows for effective strengthening low-bearing soils and formation of stone columns down to about $3 \mathrm{~m}$. In case of higher soil thickness and when longer columns are required, about fifteen ton rammers installed on a crane and dropped from 10-15 m are used. Then, the length of columns is almost doubled to 5-6 $\mathrm{m}$.

The columns formed by impulse compaction are made by repeated hammering against steel foot and driving it into soil. In that way a 1.8 to even $2.5 \mathrm{~m}$ in diameter and c. 0.80 $1.0 \mathrm{~m}$ deep crater is made, depending on the kind of soil being improved. The crater is then filled with concrete rubble of grain size $20-120 \mathrm{~mm}$, and successive course is made in the same point. Depending on low-bearing soil thickness and on the column length required, the machine runs several times until a stone column of a barrel shape is formed in the substrate.

The column is recognized as completed when no further progress is attained in immersing the foot into soil. Exemplary photos of executing the stone columns with impulse compactor are shown in Fig. 2.
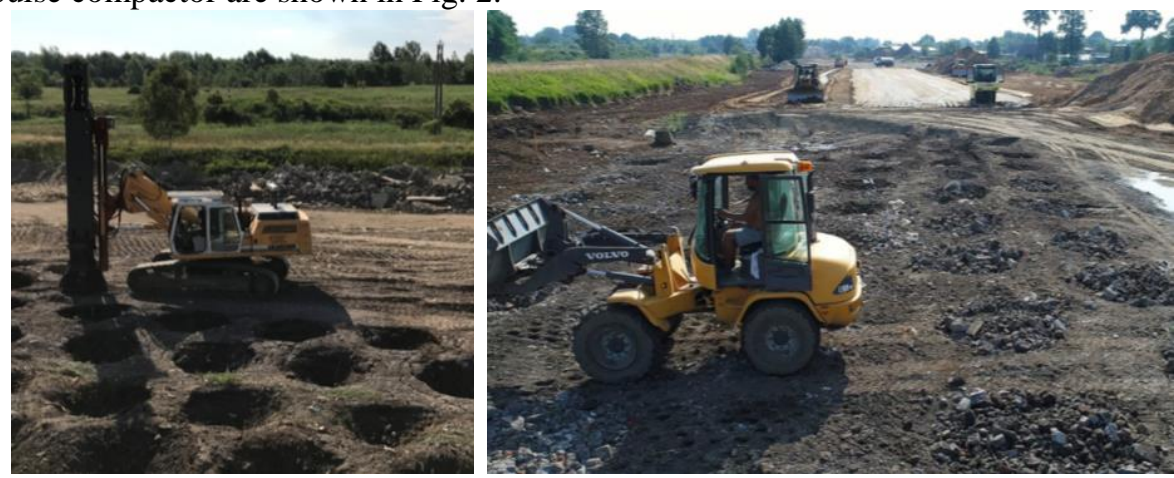

Fig. 2. Formation of stone columns: Stage 1 - ramming the craters, Stage 2 - filling in the craters with concrete rubble and rolling them thereafter. (DABI SM BUDNY Sp. z o.o. Sp. k.)

\section{Experience from calibration of substrate reinforcement technology}

In general, while assessing the effect of vibrations on surrounding structures, the German or Polish standard is used. German standard, DIN 4150-3 „Erschutterungen im Bauwesen, Einwirkungen auf bauliche Anlagen" ("Structural Vibration Part 3: Effects of vibration on structures") specifies admissible speed of vibrations depending on the frequency (Table 1).

Table 1. Admissible speeds of vibrations acc. to DIN 4150-3 [mm/s]

\begin{tabular}{|c|c|c|c|c|}
\hline \multirow{2}{*}{ Type of structure } & \multicolumn{4}{|c|}{ Frequency } \\
\cline { 2 - 5 } & $1 \mathrm{~Hz}$ & $10 \mathrm{~Hz}$ & $50 \mathrm{~Hz}$ & $100 \mathrm{~Hz}$ \\
\hline Industrial facilities & 20 & 20 & 40 & 50 \\
\hline Residential buildings & 5 & 5 & 15 & 20 \\
\hline Especially sensitive facilities & 3 & 3 & 8 & 10 \\
\hline
\end{tabular}


The Polish standard PN-B-02170:1985 "Evaluation the harmfulness of vibrations transmitted by the ground to buildings" is more extensive. It introduces the scales of dynamic effect for two kinds of buildings. The SWD-I scale refers to small buildings of compact plan up to two storeys. The SWD-II scale is applicable to buildings up to five storeys which height is less than doubled width. Five zones are distinguished in acceleration amplitude versus frequency diagram.

The zones of harmfulness are distinguished as follows:

- zone I - vibrations are not perceptible by a building,

- zone II - vibrations are perceptible by a building, but not harmful for its construction, accelerated wear of building and first scratches in coating material and plasters,

- $\quad$ zone III - vibrations harmful for building, they cause local scratches and cracks, thus weakening building construction, reducing its carrying capacity and resistance to further dynamic impacts; coating materials and plasters can come off;

- $\quad$ zone IV - vibrations of large harmfulness for building and constituting risk for people safety; generated are numerous cracks, local damages of walls and other individual elements of building;

- zone V - vibrations cause building breakdown by tumbling down the walls, falling down the floors, etc.; full risk of human life; in case of such vibrations, the building must not be used.

These zones are separated by four limits presented in nomograms in Polish standards marked by the letters:

- $\quad$ limit $\mathrm{A}$ - the bottom limit of vibrations perceptible by a building; below this limit the dynamic effects may be neglected;

- limit B - limit of building stiffness, the bottom limit of arising scratches and cracks in constructional elements,

- limit $\mathrm{C}$ - strength limit of individual building elements, the lower limit of serious constructional damages,

- limit D - limit of construction stability; the lower limit of the whole building breakdown, vibrations above this limit may cause building breakdown.

Approximate accelerations read out of the nomogram from Polish standard are shown in Table 2.

Table 2. Accelerations for foundations of buildings [mm/s2] acc. to PN-B-02170:1985

\begin{tabular}{|c|c|c|}
\hline & $\begin{array}{c}\text { SWD-I } \\
\text { (at frequency of 5-25 Hz) }\end{array}$ & $\begin{array}{c}\text { SWD-II } \\
\text { (at frequency of 1-7 Hz) }\end{array}$ \\
\hline Limit A & 0.02 & 0.025 \\
\hline Limit B & 0.10 & 0.08 \\
\hline Limit C & 0.55 & 0.4 \\
\hline Limit D & 2.40 & 3.0 \\
\hline
\end{tabular}

A great care should be used when extending the requirements to structures not covered by the mentioned standard. In practice, we may meet the facilities for which the requirements can be mitigated or intensified. Dynamic influence depends on many factors: type of construction, its technical condition, materials used, type of foundation, soil and water conditions, kind of vibrations (continuous, short-lived) and even the time of year. In the latter case, the freezing cold changes the stiffness of subsurface ground layer and vibration propagation in it. Known is the case of construction site of one subway station in Warsaw where transport of spoil with heavy trucks was totally harmless in summer, but in winter, when ground was frozen, neighbouring building subjected to some damages. In opposite go static effects, vibrations and their propagation cannot be felt intuitively. 
For static effects, we are able to imagine the loads and accompanying strains or displacements, and to estimate them in memory. In contrast, we can hardly imagine the frequency of free vibrations or acceleration expressed in fractions of $\mathrm{mm} / \mathrm{s}^{2}$. According to the arrangement of soil layers and types of foundations, not obvious ways of vibration transfer are possible. Due to such conditions at one building site, the most exposed to negative effects from executing dynamic columns were the buildings in the second building line from the area site. Hence, it is necessary to run measurements of vibrations, at least when starting with work, and also continuously in case of more difficult cases. It is then possible to correct operating conditions of machinery as the needs arise (ram dropping height for piles and columns, or frequency of vibrations for driving steel sheet piles). Such responsible approach enables to run work even in close vicinity of existing facilities. Examples of such cases are shown in papers [14-16].

\section{Control of substrate improvement quality}

In order to get as good effects as possible, impulse compacting should subject to continuous control. Most often, impulse compactor is provided with GPS guidance system and electronic control module which monitors the parameters of compacting. The GPS system allows locating the compacting points precisely, with accuracy down to several centimetres. It is of special importance when several runs are made over the same points or when it is necessary to match up work schedule and when frequent changes of work areas are necessary. The GPS system is integrated with electronic control module and makes on-line records and verifies the position of compacting foot in relation to the coordinates required for the working points.
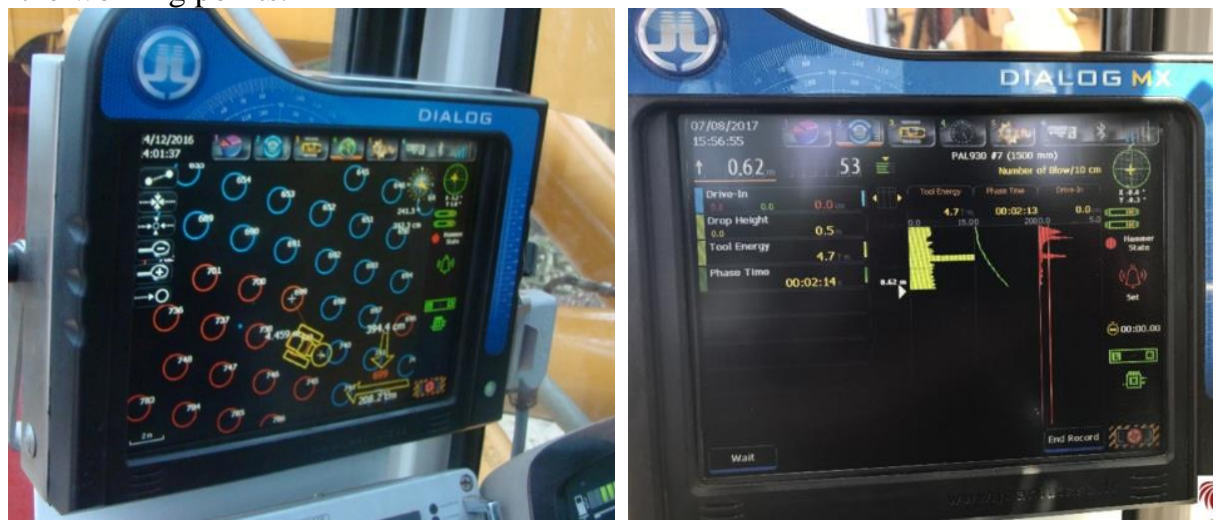

Fig. 3. View of monitors installed in machine cabin (DABI SM BUDNY Sp. z o.o. Sp. k.)

The electronic control module perpetually controls impulse compactor operation, records and transmits compaction data on a current basis. Continuous data logging is run for each point, i.e. point number, coordinates, date and time of execution, number of impulses and foot penetration per blow. These data are available at each compaction stage and can be retrieved from the system at each moment and sent from site to supervising staff. Hence, the electronic control module allows on-line supervising the quality of work. Operating parameters of the compactor are continuously displayed graphically on monitor screen located in the machine and are also sent to a server, so they can be previewed and remotely verified.

It should be born in mind that just the mere readings from control software allow to verify advanced numerical methods used during design stage [17-20]. 


\subsection{Acceptance tests for columns}

Verifying tests for compacting efficiency of the column being formed are run in two stages. The first one consists in machine operator's control and comparing the results with design parameters and those over a test segment. The second stage includes field tests in the form of rigid plate with area over $1 \mathrm{~m}^{2}$ located over column heads and loaded with machine undercarriage weighing minimum 30 tons. Tests are run using variable pressure from 0 to $250 \mathrm{kPa}$ and examining the primary and secondary load modules. Plate settlement is measured to $0.01 \mathrm{~mm}$ accuracy with electronic displacement sensors basing them on independent structure constituting a fixed point of reference. Usually, tests are made for one per 150 columns.

\subsection{Case study}

The case refers to execution of stone columns, formed with impulse compaction method, having c. $1.8 \mathrm{~m}$ in diameter and up to $3 \mathrm{~m}$ in length placed on a equilateral triangle grid $3 \times 3 \mathrm{~m}$. Due to spot improvement of the substrate, it was necessary to make a geo-mattress, which fasten together the heads of columns, to avoid uneven settlement of surface. Columns were filled with concrete rubble or various grain sizes, sharp-edged, with durable structure and fraction of $20-120 \mathrm{~mm}$.

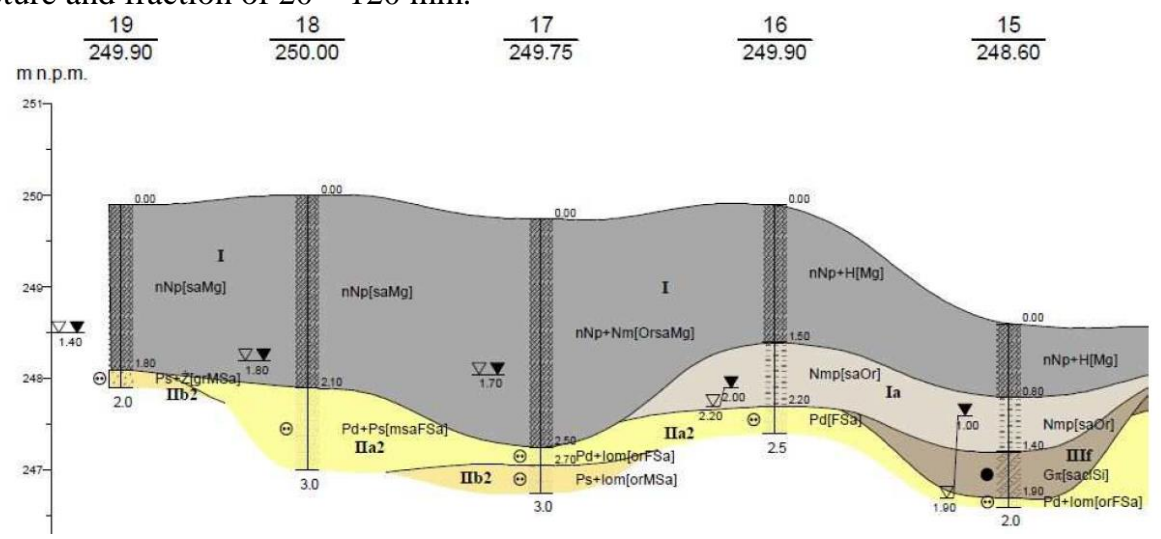

Fig. 4. Exemplary geotechnical cross-section
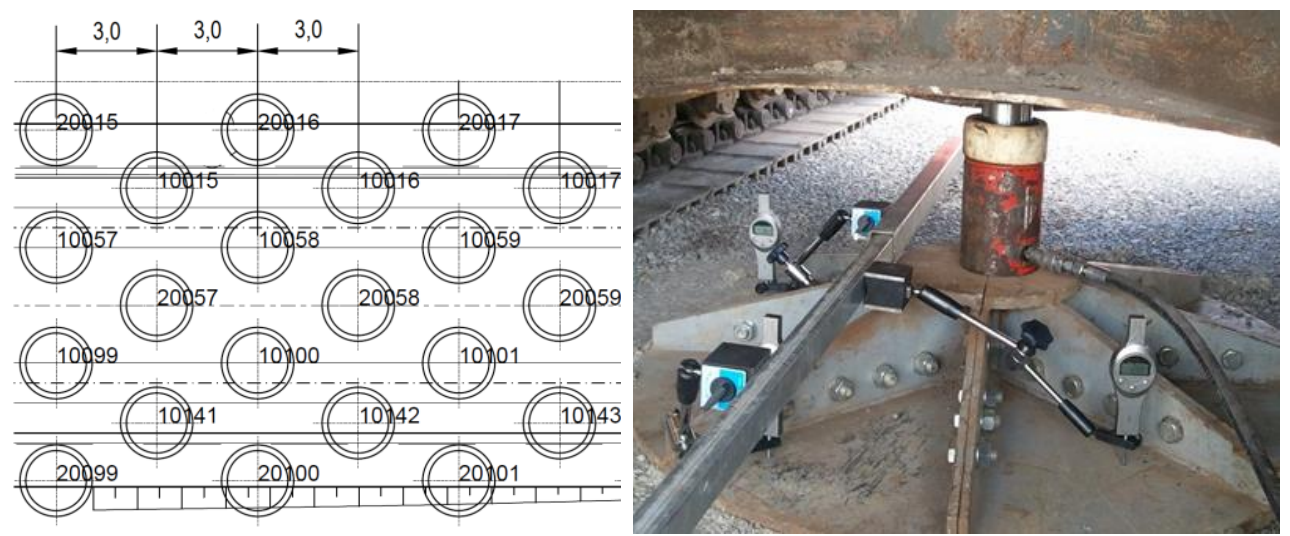

Fig. 5. Exemplary arrangement of stone columns formed with RIC method. Rigid plate with hydraulic and measuring systems (DABI SM BUDNY Sp. z o.o. Sp. k.) 

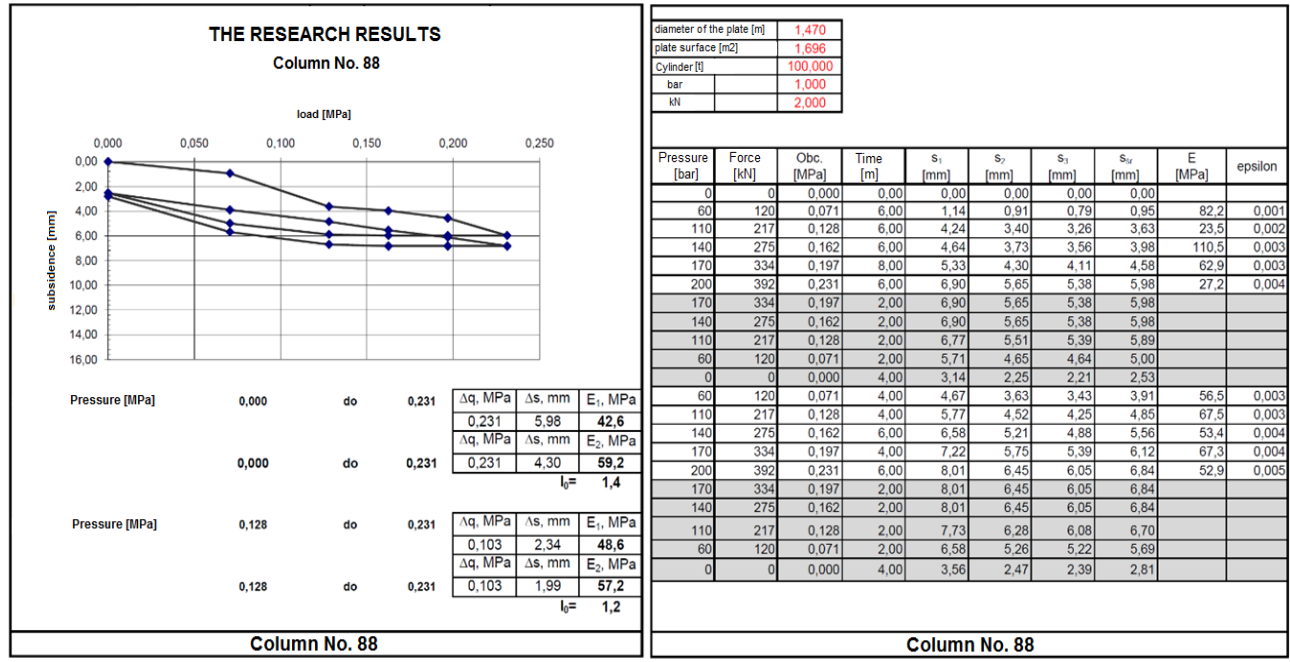

Fig. 6. Exemplary result processing for test loading of stone column in organic soil

\section{Conclusions}

The impulse compaction method enables effective improvement of substrate strength properties. It is efficient for additional compaction of non-cohesive soils. It also allows making columns out of aggregate to improve weak cohesive soils. Machinery used in this method ensures fast completion of the work, however generates noise and vibrations. Nevertheless there are effective monitoring tools enabling control over the whole process, achieving good engineering effects and running the work without negative influence to surrounding buildings and infrastructure facilities.

\section{References}

1. M. Drusa, V. Chebeň and R. Bulko, New technologies implemented in geotechnical monitoring on transport constructions, Int. Multidisciplinary Scientific GeoConference Surveying Geology and Mining Ecology Management, SGEM, 2 (1), 651-656 (2014)

2. D. Sobala, J. Rybak, Role to be played by independent geotechnical supervision in the foundation for bridge construction, IOP Conf. Series - Materials Science and Engineering, 245, 022073 (2017)

3. M. Drusa, J. Vlcek, Importance of Results Obtained from Geotechnical Monitoring for Evaluation of Reinforced Soil Structure - Case Study, Journal of Applied Engineering Sciences, De Gruyter Open, 6 (1), (2016)

4. A. Pilipenko, S. Bazhenova, Usage of crushed concrete fines in decorative concrete, IOP Conf. Series - Materials Science and Engineering, 245 (2), art. 032082 (2017)

5. S. Bazhenova, A. Pilipenko, The concrete-based high performance decorative material for severe climatic conditions, MATEC Web of Conferences, 106, 03004 (2017)

6. J. Kawalec, S. Kwiecień, A. Pilipenko, J. Rybak, Application of crushed concrete in geotechnical engineering - selected issues, IOP Conf. Series - Earth and Environmental Science, 95, 022057 (2017),

7. P. Rychlewski, Wzmacnianie gruntów pod nasypami infrastruktury komunikacyjnej, GDMT, 52 (3/2018), 36-43 (2018) [in Polish] 
8. P. Rychlewski, Wzmacnianie podłoża gruntowego pod inwestycje infrastrukturalne, Materiały budowlane, 547 (3/2018), 6-8 (2018) [in Polish]

9. J. Rybak, K. Schabowicz, Survey of vibrations generated in course of geotechnical works. NDE for Safety: $40^{\text {th }}$ int. conf. and NDT exhibition: proceedings, Czech Republic, Brno University of Technology, 237-246 (2010)

10. W. Brząkała, A. Herbut, J. Rybak, Recommendations for ground vibrations survey in course of geotechnical works. $14^{\text {th }}$ International Multidisciplinary Scientific GeoConference SGEM 2014, Albena, Bulgaria, 2, 747-754 (2014)

11. B. Parkasiewicz, M. Kadela, P. Bętkowski, R. Sieńko, Ł. Bednarski, Application of Structure Monitoring Systems to the Assessment of the Behaviour of Bridges in Mining Areas, IOP Conf. Ser: Mater. Sci. Eng., 245 (3), 032018 (2017)

12. F. Oliveira, I. Fernandes, Influence of geotechnical works on neighboring structures, $17^{\text {th }}$ Int. Multidisciplinary Scientific GeoConference, SGEM 2017. 12, 993-1001 (2017)

13. M. Wyjadłowski, Methodology of dynamic monitoring of structures in the vicinity of hydrotechnical works - selected case studies, Studia Geotechnica et Mechanica, 39 (4), 121-129, (2017)

14. J. Rybak, J. Pieczyńska-Kozłowska, Vibration monitoring as a tool for a calibration of geotechnical technologies, $14^{\text {th }}$ Int. Multidisciplinary Scientific GeoConference SGEM 2014, Albena, Bulgaria, 2, 1043-1050 (2014)

15. J. Rybak, A.G. Tamrazyan, Calibration of rapid impulse compaction on the basis of vibration velocity control, $16^{\text {th }}$ Int. Multidisciplinary Scientific GeoConference SGEM 2016, Albena, Bulgaria, 1, 715-722, (2016)

16. A. Herbut, J. Rybak, Guidelines and recommendations for vibration control in the case of rapid impulse compaction, Advances and trends in engineering sciences and technologies II, CRC Press, Taylor \& Francis Group, 761-766, (2017)

17. P. Kanty, J. Sękowski, Model tests of phenomena occurring during stone column formation, Architecture Civil Engineering Environment - ACEE, 1, 45-53 (2011)

18. W.T. Sołowski, S.W. Sloan, P.T. Kanty, S. Kwiecień, Numerical simulation of a small scale dynamic replacement stone column creation experiment, $3^{\text {rd }}$ Int. Conf. on Particle-based Methods Fundamentals and Applications, PARTICLES, 522-533 (2013)

19. J. Kawalec, T. Warchał, Dynamic Replacement Columns with Aggregate Transition Zone Stabilized by Geosynthetics for Embankment Foundation over Weak Deposits, XVI European Conf. on Soil Mech. and Geotech. Eng., Edinburgh, 1511-1516 (2015)

20. P. Kanty, K. Sternik, S. Kwiecień, Numerical analysis of consolidation of embankment subsoil reinforced with dynamic replacement stone columns, Technical Transactions, 2-Ś' (24), 79-100 (2015) 